\title{
Conflitos sociais, práticas políticas e cultura da honra: um itinerário de pesquisa na construção da violência como objeto sociológico
}

Francisco Thiago Rocha Vasconcelos*

BARREIRA, César. Cotidiano despedaçado: cenas de uma violência difusa. Fortaleza, CE: Universidade Federal do Ceará/Funcap/CNPq-Pronex; Campinas, SP: Pontes Editores, 2008. 262 p.

"Cotidiano despedaçado: cenas de uma violência difusa" (2008) reúne os principais momentos dentro da trajetória de pesquisa do sociólogo César Barreira, em mais de 30 anos de trabalho intelectual. Sua produção exemplifica um importante capítulo da história dos estudos sobre violência nas Ciências Sociais brasileiras, demonstra, especialmente, as contribuições presentes nos estudos sobre conflitos no campo para a discussão geral sobre criminalidade urbana violenta e segurança pública no Brasil.

O título da coletânea de textos representa bem as duas ênfases principais abordadas por Barreira. O "Cotidiano Despedaçado" faz referência ao filme "Abril Despedaçado", de Walter Salles, cujo tema diz respeito às lutas entre famílias pela posse da terra e os valores morais que regulam a vida em sociedade dentro desse contexto. A vingança como mecanismo de administração dos conflitos e os valores de coragem, valentia e virilidade, ligados a um código de honra, constituem o universo simbólico que atravessa o campo de pesquisa do sociólogo.

Doutorando junto ao Programa de Pós-Graduação em Sociologia da Universidade de São Paulo. Endereço eletrônico: ft_rocha@yahoo.com.br. 
O subtítulo, por sua vez, diz respeito ao aumento da criminalidade e das práticas violentas e o seu impacto na convivência social no mundo contemporâneo. A sensação de insegurança frente à possibilidade de ser alvo de práticas violentas alimentaria o surgimento de uma "cultura do medo" e o reforço da desigualdade social pela dificuldade no reconhecimento entre as diferenças. Este é o cenário de uma "violência difusa", presente em diversas situações sociais, principalmente nas grandes cidades, e passível de atingir todas as classes sociais, gêneros e faixas etárias, caracterização que não descarta, frisa o autor, as "vítimas preferenciais" da violência, aqueles que vivenciam situações de maior vulnerabilidade social. Um contexto que, em um segundo momento, começa a aparecer com mais força nas pesquisas desenvolvidas pelo autor, junto à problemática do funcionamento das instituições de segurança pública.

Ter partido de estudos sobre questões agrárias e conflitos sociais permitiu ao sociólogo uma aproximação diferenciada com o tema da violência, não tanto pela questão criminal e urbana e mais pelo enfoque das relações de poder e dos movimentos sociais. Uma das consequências dessa aproximação diferenciada é a inexistência de um corte com relação à produção da Sociologia sobre a formação cultural brasileira. Autores como Gilberto Freyre, Sérgio Buarque de Hollanda, Maria Sylvia de Carvalho Franco, Maria Isaura Pereira de Queiroz, fazem parte do seu aporte teórico. O diálogo e as tensões entre, por um lado, a tradição dos códigos culturais de honra e da estrutura de dominação fundada na posse da terra, o uso da violência como recurso na solução dos conflitos e, por outro, a questão do monopólio legítimo da violência física frente à contemporaneidade dos processos de modernização e de crescimento da criminalidade e seus resultados na construção dos conflitos e das subjetividades é o principal destaque dentro desta perspectiva.

O livro, portanto, traça um caminho de construção de um problema social em uma questão sociológica que passa pela aproximação entre os referenciais da Sociologia rural e da Sociologia da violência, movimento entre áreas temáticas que pode ser observado dentro da trajetória do autor: em sua graduação, César Barreira se voltou para o tema da parceria na cultura do algodão no sertão cearense, que lhe estimulou a investigar a problemática da organização 
dos sindicatos rurais e a estrutura do poder dos sertões, tema de seu mestrado (BARREIRA, 1992). A repressão violenta às contestações dos trabalhadores rurais, o assassinato de líderes camponeses, fizeram com que o pesquisador direcionasse o seu olhar para o tema dos crimes de mando ligados à questão da terra e à questão da segurança pública (Idem, 1998). Atualmente suas atenções se dirigem para os "bandidos de honra" na Ilha de Córsega, na França, incursão sugestiva de possibilidades comparativas entre fenômenos sociais, abordada no capítulo Honra e Conflito na Córsega.

O espaço agrário é analisado em quatro capítulos, relativos ao lugar da disputa pela terra e a exclusão social na configuração da violência, subsídio para a análise do massacre de Eldorado do Carajás e do lugar da família no mundo do crime. A desigualdade social, o uso dos órgãos de segurança pública na defesa da propriedade privada, o embaralhamento das fronteiras entre o público e o privado e o universo dos crimes por encomenda, constroem um campo muito diferente da imaginada "paz agrária".

O tema da pistolagem é revisitado em quatro capítulos, que permitem visualizar o caminho percorrido pelo autor, das perguntas e formulações ainda preliminares, a conclusões mais aprofundadas sobre os significados que circunscrevem as variadas manifestações do fenômeno. Em sua primeira investida, 0 pistoleiro e a política: $a$ morte por encomenda, publicado em 1992, a pistolagem está situada como recurso da classe dominante nos conflitos envolvidos, ou na questão da luta pela terra, quando os alvos principais são os líderes camponeses ou agentes pastorais, ou na disputa pela representação política, na qual se visa a eliminação do opositor na política partidária, em um cenário de confronto entre famílias dominantes. No primeiro caso, a prática se relaciona à preservação do domínio político-econômico e se caracteriza pelo sentido de dar visibilidade, "espalhar o medo" para ocasionar uma desmobilização; no segundo, é a reprodução do mando político que está em jogo, sendo acionados mecanismos mais sofisticados de anonimato.

A pistolagem é analisada tendo em vista a hipótese de Hannah Arendt a respeito da violência como expressão da fragilidade do poder. Nesse sentido, a pistolagem é utilizada na medida em que se estabelecem fissuras na dominação tradicional, prática recorrente 
no "tempo da política", período da radicalização das disputas entre as facções. As implicações deste cenário para a construção do monopólio legítimo da violência física por parte do Estado são então colocadas como tema de análise, a partir da campanha de combate ao crime de pistolagem, organizada no fim dos anos 1980 pelo governo do Estado, do papel das instituições de segurança pública, da montagem do processo judiciário e das repercussões nos meios de comunicação. $\mathrm{O}$ autor ressalta que, se o julgamento de pistoleiros representou um marco na aplicação da lei, ao mesmo tempo teria demonstrado também que o poder público não obteve sucesso em penetrar na rede de relações que envolve este crime, posto que os mandantes não figuraram nos processos.

Esta primeira discussão já aponta para importantes direcionamentos na análise do fenômeno, consolidadas no capítulo Novas configurações dos pistoleiros: repensando práticas antigas. O estudo da pistolagem passa a incorporar referenciais que vão para além do cenário da dominação política tradicional, centrados na terra e no voto. Tendo origem no espaço agrário, as novas manifestações do fenômeno se relacionam agora também com a sociabilidade no mundo urbano e a violência difusa do cotidiano. Entrelaçando tradição e modernidade, o pistoleiro se afasta das atividades agrícolas e dos vínculos com um patrão, passa a morar nas periferias das grandes cidades, integrado a uma rede articulada no nível intermunicipal e interestadual. As relações pessoais começam a dar espaço para relações impessoais, ligadas à "profissionalização" do "serviço". O pistoleiro deixa de lado o cavalo e adota a moto e o capacete como instrumentos, atuando não só na eliminação de desafetos políticos, mas em conflitos interpessoais, que envolvem um amplo espectro como brigas por dívida, infidelidade, ciúme, vingança.

O monopólio legítimo da violência física e a pacificação dos costumes, elementos importantes de um "processo civilizador" (ELIAS, 1994), encontram dificuldades para se concretizarem não somente pela desigualdade na aplicação da lei, mas também pela legitimidade popular do uso da força física na resolução dos conflitos, agravada por um cenário urbano de violência difusa.

A segurança pública e as práticas policiais são outros temas importantes nas pesquisas de César Barreira. Ganha destaque o ca- 
pítulo Em nome da lei e da ordem: a propósito da política de segurança pública, resultado de uma discussão coletiva, reunida em livro (BARREIRA, 2004). As transformações instituídas na área da segurança pública a partir do "governo dos empresários" e as crises enfrentadas ao longo de 15 anos é o principal objeto de discussão ${ }^{1}$. Como se realizou, em governos marcados pela intenção de demarcar a diferença com o passado "atrasado" e "irracional" do "tempo dos coronéis", a manutenção da lei e da ordem tendo em vista a herança autoritária dos governos militares (ADORNO, 2000) e a demanda popular por segurança? As crises institucionais ocasionadas pelos "escândalos" de violência policial e corrupção, como momentos de maior transparência das fissuras no tecido social, foram o principal foco da análise. $\mathrm{O}$ estudo das modificações políticas e técnicas advindas destas crises procurou evidenciar a questão da segurança pública e dos direitos humanos no centro do debate político e acadêmico sobre a legitimidade do Estado de Direito no Ceará.

Ainda dentro desta temática, um capítulo importante é Lugar de policial é na política?, no qual a história de Maracanaú, cidade metropolitana de Fortaleza, considerada pela imprensa e órgãos de segurança pública como o maior celeiro de pistoleiros do Estado, é analisada a partir das relações entre política e violência. $O$ autor procura compreender como se dá o fenômeno da inserção dos policiais na política diante de um quadro de descrédito da opinião popular sobre o trabalho policial. Um objeto - trajetórias policiais na política - que constituirá uma relevante perspectiva na orientação de futuros pesquisadores.

Não se poderia deixar de destacar, nesta resenha, os principais fundamentos teóricos e metodológicos que serviram de guias nas pesquisas realizadas pelo autor. Os capítulos Violência e cordialidade na sociedade brasileira e Pesquisando "temas perigosos": as armadilhas simbólicas da pesquisa" servem como um roteiro, nesse sentido. A

1 "Governo dos empresários" ou "governo das mudanças" são termos comuns utilizados para demarcar o período de quebra na aliança que sustentava os "antigos coronéis” (Virgílio Távora, César Cals e Adauto Bezerra) e de surgimento de novas lideranças ligadas ao Centro Industrial do Ceará (CIC) que teriam a hegemonia política nos anos 1990, nos mandatos de Tasso Jereissati (1987-1990), Ciro Gomes (1991-1994) e novamente Tasso Jereissati (1995-2002). 
partir dos referenciais de Max Weber sobre o monopólio legítimo da violência física, de Hannah Arendt sobre a violência como demonstração da fragilidade da política, de Norbert Elias sobre o processo civilizador e de Georg Simmel sobre o conflito como fundamento das relações sociais, Barreira procura as ferramentas conceituais e questões teóricas para uma análise das relações sociais de modo não culturalista, ou seja, atenta às variáveis institucionais e contextuais no percurso histórico. É desse modo que traça um diálogo importante com as narrativas clássicas das Ciências Sociais sobre a formação cultural da sociedade brasileira, que lhe permite colaborar para a compreensão dos fenômenos na tensão e interlocução entre tradição e modernidade, conferindo sentido ao presente.

Nesse sentido, o autor, partindo das questões teóricas ligadas aos conflitos de classe e dominação política no campo, tematiza a construção de subjetividades liminares entre as classificações criminais e as referências tradicionais de honra presentes na cultura brasileira. A violência é entendida como construção social e cultural e não como fenômeno dado. Embora considere as práticas classificadas pela sociedade como criminosas, Barreira procura dar conta também do modo como os criminosos dão significado às suas práticas. Desse modo, aponta para o perigo de um viés "positivista" de análise e do julgamento social no estudo da violência. Esta perspectiva é ilustrada pelas várias fontes de pesquisa a que recorre o pesquisador (jornais, documentos oficiais, registros da cultura popular, entrevistas com agentes do Estado e criminosos) e pela sensibilidade antropológica no que diz respeito ao método: os limites e dificuldades da investigação de um "tema perigoso", diante da distância entre os valores morais do pesquisador e do entrevistado, difícil relação constituída na lógica da suspeita a demandar estratégias de sedução e empatia com os entrevistados, é o ponto alto de uma narrativa sobre as questões éticas e metodológicas do trabalho de pesquisa.

O livro se encerra com um outro lado da prática do sociólogo, o desempenho de um papel intelectual e político no debate público. É reunido um conjunto de escritos, publicados em jornais, sobre temas diversos como: o significado das crises no sistema penitenciário, por ocasião das rebeliões organizadas pelo PCC; a 
dificuldade em estabelecer acordos, contratos e regras de convívio na sociedade e a violência em família; a crítica à intervenção militar no Rio de Janeiro; as relações de poder e de violência na regulação da segurança na indústria do turismo; a aceitação social de práticas violentas, como os linchamentos, e o que a morte do índio Galdino Jesus dos Santos revela sobre o apartheid social no Brasil; o abuso de poder na atuação policial e o debate sobre o referendo acerca da proibição da venda de armas de fogo e munição, temas analisados na busca de dar algum sentido aos acontecimentos que causam o assombro e a indignação popular, assim como influenciar a reflexão e os encaminhamentos políticos a serem tomados.

\section{Referências}

ADORNO, S. Insegurança versus direitos humanos - entre a lei e a ordem. In: Tempo Social, Revista de Sociologia da USP, v.11, n.2. São Paulo: USP, 2000.

BARREIRA, C. Trilhas e atalhos do poder: conflitos sociais no sertão. Rio de Janeiro: Rio Fundo, 1992.

. Crimes por encomenda: a pistolagem no cenário brasileiro. Coleção Antropologia da Política. Rio de Janeiro: Relumé Dumará, 1998.

. (Org.). Questão de Segurança: políticas governamentais e práticas policiais. Rio de Janeiro: Relume Dumará, 2004.

ELIAS, N. O processo civilizador: uma história dos costumes. Rio de Janeiro: Jorge Zahar, 1994. 
